\title{
sciendo
}

\section{Personal Identity: The Simple and Complex Views Revisited}

\begin{abstract}
Harold Noonan
University of Nottingham

DOI: $10.2478 /$ disp-2019-0001

BIBLID [0873-626X (2019) 52; pp.9-22]

Abstract

Eric Olson has argued, startlingly, that no coherent account can be given of the distinction made in the personal identity literature between 'complex views' and 'simple views'. 'We tell our students,' he writes, 'that accounts of personal identity over time fall into [these] two broad categories'. But 'it is impossible to characterize this distinction in any satisfactory way. The debate has been systematically misdescribed'. I argue, first, that, for all Olson has said, a recent account by Noonan provides the coherent characterization he claims impossible. If so we have not been wrong all along in the way he says in what we have been telling our students. I then give an account of the distinction between the reductionist and non-reductionist positions which makes it different from the complex/simple distinction. The aim is to make clear sense of the notion of a not simple but non-reductionist positionwhich seems an eminently reasonable possibility and something it may also be useful to tell our students about.
\end{abstract}

\section{Keywords}

Simple view, complex view, personal identity, Olson, reductionism.

In his (2012) Eric Olson argues, startlingly, that no coherent account can be given of the distinction made in the personal identity literature between 'complex views' and 'simple views' (see, notably, Parfit 1982). 'We tell our students,' he writes, 'that accounts of personal identity over time fall into [these] two broad categories'. But 'it is impossible to characterize this distinction in any satisfactory way. The debate has been systematically misdescribed' (2012: 44). 
In the course of his search for the simple view one of the many accounts Olson argues against is the recent proposal of Noonan in his (2011) (see also Noonan 2012 and Curtis and Noonan 2015). I think that his argument against this proposal is mistaken. My first aim in what follows is to identify the flaw in Olson's criticism of Noonan. If I am right it remains a possibility that Noonan has provided the coherent account of the simple/complex distinction Olson denies to be possible. If so we have not been wrong all along in the way he suggests in what we have been telling our students.

My second main aim in what follows is to use resources from Noonan not utilised by him to give a sense to the non-reductionist/ reductionist distinction which makes it different from the simple/ complex distinction. The motivation for doing so is to accommodate the possibility of what seems the eminently reasonable position that there are substantial necessary conditions of personal identity over time, but no informative sufficient condition. For example, some might hold that memory or continuity of memory is necessary for personal identity, pace the prominent simple theorists Swinburne (2012) and Chisholm (1969). But they might also think, with Butler, that memory presupposes personal identity and so cannot provide an informative sufficient condition. Moreover, they might deny that any non-personal-identity presupposing notion, like Shoemaker's (1984) quasi-memory, can be employed to give an informative sufficient condition. It is tempting to deny that such a position is simple, since it rules out possibilities Swinburne and Chisholm make it central to their position to insist on, but at the same time to say that it is non-reductionist, since it also rules out the possibility of defining personal identity in other terms in the way Shoemaker thinks possible. My second aim is thus to make clear sense of the notion of such a not simple but non-reductionist position — which is also something I think it may be useful to teach our students.

As noted the 'simple' versus 'complex' terminology was introduced by Parfit (1982) to classify historical positions and to explain a significant difference between contemporary philosophers. On the historical issue, Parfit mentions Locke (1694/1961) and Hume (1739) 
as defenders of the complex view (henceforth, complex theorists)); Reid (1785/1941) and Butler (1736) as simple theorists. As regards recent philosophy, standardly Chisholm (1969) and Swinburne are also classified as simple theorists. Madell (1981) is another. Shoemaker (2012) and Parfit himself are self-declared complex theorists, whilst Lewis (1976) also belongs in this group.

The most important difference between Butler and Reid on the one hand and Locke and Hume on the other is that the former emphasize the distinction between personal identity over time and the identity over time of other things - artefacts, plants and animals whereas the latter downplay this.

Specifically, Butler (1736) and Reid (1941) say that personal identity over time is identity in a 'strict and philosophical sense' or 'perfect identity', but they consider the 'identity' over time of other things - whether natural or artificial, as 'imperfect' identity only, or as identity only in a 'loose and popular' manner of speaking; something which, as Reid puts it, we call identity only for 'conveniency of speech'.

It goes with the conception of personal identity that Butler and Reid have that questions of personal identity must have 'Yes' or 'No' answers, knowable or not, and are never a matter for a verbal decision, unlike the identity over time of artefacts, plants and animals.

Locke and Hume, by contrast, play down the distinction between personal identity and the identity of other things. They do not say that it is more 'perfect' or 'strict and philosophical' than the identity of anything else. In fact, Locke makes the analogy between personal identity and the identity of plants central to his account: as sameness of life makes for identity in the case of plants so sameness of consciousness makes for identity in the case of persons. Hume insists that the identity we ascribe to 'the mind of man' is of a like kind with that which we ascribe to vegetable and animal bodies.

But how is the distinction between the simple and complex views to be made clear?

Parfit attempts to capture the distinction by suggesting that a simple theorist holds that the fact of personal identity is a 'further fact' not 'consisting' in the holding of any 'other more particular facts' which can be 'described impersonally' (1982: 227; 1984: 210), whereas this is denied by the complex theorist. 
But Parfit's explanation has not been found luminous. One criticism of it is just that identity can never consist in other, more particular facts: the identity of a thing with itself cannot consist in anything else, and the identity of a thing with something other than itself can never consist in anything at all, since nothing is identical with anything else. Suggestive though Parfit's words are, we need a more illuminating account of the distinction between the complex and simple views. Various authors have attempted to provide the required account. Olson's purpose is to argue that none of them have succeeded, including Noonan. It is his criticism of Noonan's account I challenge.

Noonan (2011) starts from the Lewisean thought (1986: 192-3) that there are no problems about identity, and, in particular, no problems about identity over time: 'We do state ... genuine problems in terms of identity. But we needn't state them so. Therefore, they are not problems about identity.' Consider any putative problem about whether a thing $x$ is identical with a thing $y$. There are exactly two possibilities (i) $x$ is $y$ or (ii) $x$ is not $y$. In case (i) the putative problem is about the conditions under which a thing is identical with itself. But there cannot be such a problem because it is a conceptual truth that everything is identical with itself. In case (ii) the putative problem is about the conditions under which a thing is identical with something else. But a thing cannot be identical with something else, so there is no such problem. Hence, Lewis endorses the No Identity Problems Thesis (NIP).

(NIP) There can be no problems about the conditions under which something $x$ is identical with something $y$.

The NIP thesis applies to putative problems about the conditions under which a persisting thing of kind $K$ at a time $t$ is identical with a persisting thing of kind $K$ at another time $t *$ So there can be no such problem.

However, we do ask questions that are apparently about the conditions of identity over time of persisting things. For example, we do ask: under what conditions can a restaurant or river or person $x$ 
at one time be identical with a restaurant or river or person $y$ at another. Noonan's thought is that, in accordance with Lewis's insight, such questions need to be rephrased to capture the sense they have.

Specifically, he thinks, the question about persons can be rephrased as:

P1: What relations R satisfy the schema 'Necessarily, if $x$ is a person then if $x$ exists at $t$ and $t *$ then $\mathrm{R} x t t^{*}$ '?

This question does not ask for conditions of identity, it asks for conditions of personhood. Specifying a relation satisfying the P1 schema (for example, it may be suggested, ' $x$ has the same body at $t$ and $t$ ' or 'if $t$ is later than $t^{*} x^{\prime}$ 's psychological state at $t$ is causally dependent on $x$ 's psychological state at $t{ }^{*}$ ') gives us a sentence expressing a constraint on how a person can vary across time, a sentence that tells us that a person cannot survive certain changes.

Now Noonan notes three kinds of relation satisfying the P1 schema.

First are relations that trivially satisfy the P1 schema, relations that are logically entailed by ' $x$ is a person, $x$ exists at $t$ and $x$ exists at $t^{*}$ ', e.g., if $t$ is not $t^{*}$ there are two times at which $x$ exists.

Second are relations redundantly satisfying the P1 schema. These are relations that are entailed by the totality of synchronic constraints on being a person. The P1 schema is diachronic. Its instances tell us what it is to be a person over time, but they do not tell us anything about what it is to be a person at a time. There will, however, be constraints on what it is to be a person at a time, given by answering the question:

SP: Which properties $P$ satisfy the schema 'Necessarily, if $x$ is a person then if $x$ exists at $t, x$ has $\mathrm{P}$ at $t$ '?

in which ' $\mathrm{P}$ ' represents a property of $x$ that says nothing about any other times than $t$.

For example, it may be said that if a person exists at a time the person must be actively engaged in thought at the time (a position Locke ascribed to Descartes), or that if a person exists at a time the person must have some shape and size at that time (a materialist position).

The third kind of relation Noonan notes is one that is 
identity-involving. A relation is identity-involving just in case its holding between a person at one time $t$ and another $t^{*}$ requires that something other than a person exists both at $t$ and $t^{*}$ (for example, having the same brain is identity-involving if brains are not persons).

Using these notions Noonan (2011) gives his account of the distinction between the simple and complex views. The complex view is that there is a (at least one) non-trivial, non-redundant, non-identity-involving diachronic constraint on personhood (for example, causal dependence of later psychological states on earlier ones). The simple view is that all diachronic constraints are trivial, redundant or identity-involving. ${ }^{1}$

It may be wondered why Noonan does not rest with characterizing the complex view just as the view that there is a non-trivial, non-redundant diachronic constraint on personhood. Why does he insist on the lengthier characterization, i.e., the one involving the non-identity constraint? He explains that he thinks the shorter characterization inadequate since one version of the simple view is that, although persons are not souls (because persons have material parts as well), the identity of a person is constituted by the identity of his soul-you go where your soul goes (Swinburne 1984). According to this position there is a non-trivial, non-redundant constraint on personhood: if $x$ is a person who exists at $t$ and $t^{*}$ then $x$ has the same soul at these times. Nevertheless, the position that personal identity is constituted by soul identity (if nothing more can be said about soul identity (Swinburne 2012), that is, if persistence of soul does not entail any non-identity-involving, non-trivial, non-redundant constraint on personhood) should surely, Noonan says, be thought

\footnotetext{
${ }^{1}$ Noonan (2011) adds in a footnote (fn. 2) 'More precisely, the simple view is that the concept of a person is the concept of a sort of persisting object which is not governed by non-trivial, non-redundant, non-identity-involving diachronic constraints. ... the complex view [is the view] that the concept of a person is the concept of a sort of persisting object which is governed by such constraints'. So, views according to which the concept of a person is not a sortal concept, e.g., animalism, according to which it is a functional concept, like Olson's concept of a locomotor (Olson 1997), are neither simple nor complex. Insofar as we have not been drawing our students' attention to the possibility of such views (as Noonan (2003: 8) in fact does) then we have been misleading them. But it does not follow that no coherent account of the simple/complex division can be given, which is the charge by Olson I am challenging.
} 
of as an instance of the simple view of diachronic personal identity. A position according to which the only non-trivial, non-redundant diachronic constraints on personhood are identity-involving ones (as is the case on Swinburne's view) cannot be thought of as an instance of the complex view. So the longer characterization of this view is needed. ${ }^{2}$

Olson's objection (2012: 57) is:

... Noonan's proposal makes the simple view so strong that no one actually holds it. No philosopher I know of would accept that a person could be wholly material at one time and wholly immaterial at another. If you are now made up entirely of matter, then no being that is not made up even partly of matter at some other time can be you. Likewise, if you are wholly immaterial now ... then you could not come to be made up entirely of matter. This is not a synchronic condition for personal identity: it does not follow from what it is to be a person, even a human person, at a particular moment. From the proposition that $x$ is a human person at $t$, it does not follow either that $x$ is material at $t$ or that $x$ is immaterial at $t$, never mind that $x$ is material or immaterial at any other time.... Nor is the condition trivial or identity-involving. If so Noonan's proposal implies that you hold a simple view only if you reject this condition; only if you think that it is possible for one of us to change from being material to being wholly immaterial or vice versa. But every supposed advocate of the simple view accepts the condition.

What is wrong with this argument is the statement: 'From the proposition that $x$ is a human person at $t$ it does not follow either that $x$ is material or that $x$ is immaterial'. This asserts that it is possible

\footnotetext{
${ }^{2}$ What if someone were to propose a four-dimensionalist (perdurantist) version of Swinburne's view, according to which personal identity consists in soul identity, but soul identity requires a relation between 'soul-stages'? If the relevant relation is such that its obtaining between the stage of a person $x$ 's soul at $t$ and the stage of his soul at $t *$ ensures the satisfaction by person $x$ of a non-trivial, nonredundant, non-identity-involving constraint on personhood, this theory would be a version of the complex view. Such a position would, however, be repugnant to Swinburne, and is held, as far as I know, by no one. (Thanks to Penelope Mackie for raising this issue.)
} 
for there to be wholly material persons and possible for there to be wholly immaterial persons. However, many materialists will in fact deny the possibility of wholly immaterial persons and many dualists will in fact deny the possibility of wholly material persons. ${ }^{3}$ But a theorist will be at risk on Noonan's proposal of being classified as a complex theorist on the basis of Olson's argument only if he accepts both the possibility of wholly immaterial persons and the possibility of wholly material persons. So many materialists and more importantly (since materialists will most likely be complex theorists anyway) many dualists will in fact not be at risk of being classified as complex theorists on this basis since though they will accept that no person can be wholly material at one time and wholly immaterial at another, they will regard this as, in Noonan's language, a redundant diachronic constraint, one entailed by the synchronic constraints on personhood. Hence Olson has not shown that Noonan's proposal makes 'the simple view so strong that no one actually holds it'. For all his argument shows many dualists may in fact hold it.

Of course, according to Noonan's proposal a simple theorist must allow possibilities that many, perhaps most, philosophers, including perhaps most dualists, will reject. A theorist whose position is an instance of the simple view must allow the possibility of a person whose history satisfies no non-trivial, non-redundant, non-identityinvolving constraint. But this is no objection to Noonan because that is how the simple view is standardly understood.

Thus Madell, a proponent of the simple view, writes (1981: 107):

[W] hat unites the experiences [of a person] is that they belong, unanalyzably, to the one mind and ... their doing so is compatible with the absence of objective connection between them.

Chisholm (1969: 138), another simple theorist, says that my future

\footnotetext{
${ }^{3}$ But some materialists may be functionalists who think that in actual fact all mental states are functionally realized in wholly material states (so in this sense are materialists) but also think that in other possible worlds some are functionally realized in wholly immaterial states, and some dualists may be functionalists who think that in actual fact all mental states are functionally realized in wholly immaterial states but in other possible worlds some are functionally realized in wholly material states (see Shoemaker 1984: Chapters 7 and 13, he calls functionalists of this kind 'minimal' dualists).
} 
experiences need not be linked 'by any of our present criteria of personal identity to my present self'.

Swinburne (2012: 105) has recently expressed the simple view as follows:

On the simple view, a person $\mathrm{P}_{2}$ at a time $t_{2}$ can be the same person as a person $\mathrm{P}_{1}$ at a time $t_{1}$ whatever the physical or mental properties and whatever the body possessed by each person. $\mathrm{P}_{2}$ at $t_{2}$ may not remember anything done or experienced by $\mathrm{P}_{1}$ at $t_{1}$ or earlier and may have an entirely different character and totally different body (including brain) ... continuities of the kind mentioned are not necessary for personal identity. $^{4}$

Finally, Shoemaker (2012:129) says that a simple theorist must acknowledge the possibility of a 'series of property-instances that is the career of a persisting person though there are no causal relations and no relations of counterfactual dependence between successive members', since 'the diachronic unity relation cannot be simple and unanalyzable if its obtaining requires spatio-temporal continuity or causal connectedness'.

I conclude that it remains open, for all Olson has said, that Noonan has given a successful account of the simple/complex distinction and that we have not been systematically misdescribing the debate to our students in the way he suggests.

I now turn to the account of the non-reductionist/reductionist distinction.

There seems the possibility of a position according to which there are substantial necessary conditions on personal identity over time,

\footnotetext{
${ }^{4}$ Harking back to Olson's argument against Noonan, perhaps Madell would even allow (or his words may imply, whatever he intends) the possibility of a person's being wholly immaterial at one time and wholly material at another, so that he would not accept the impossibility of such a transformation even as a redundant diachronic constraint. But I doubt that Chisholm and Swinburne would agree - they would simply say that there could not be both wholly immaterial persons and wholly material persons (in fact, Swinburne has a proof that every person must have an immaterial part (Shoemaker and Swinburne 1984: 16)), so that while the constraint exists it is redundant.
} 
but no informative sufficient condition can be given. For example, someone might hold that memory or, at least, continuity of memory, is necessary for personal identity. But he might insist, with Butler, that memory presupposes personal identity so that an informative sufficient condition cannot be given in terms of it. Moreover, he might deny that any other informative sufficient condition can be given. On the account Noonan gives someone holding this position would count as a complex theorist, but this position is clearly intermediate between the simple view of Chisholm and Swinburne and the reductionist position Shoemaker embraces. It is tempting to describe this position as that of a complex theorist who is not a reductionist. The aim of this section is to use resources from Noonan to give clear sense to this description.

To put it roughly for the moment, it may be said that a reductionist must not only hold, with the complex theorist, that (a) there are non-trivial, non-redundant, non-identity-involving diachronic constraints (necessary conditions) on personhood but also hold that (b) the totality of such constraints constitutes a sufficient condition of personal persistence.

To put this thought more exactly let us begin with another question which is apparently about the conditions of personal identity over time. Then we can look at the way Noonan tries to reformulate it so as to reveal it as really a question about conditions of personhood.

We can ask not only: under what conditions can a person existing at one time be identical with one existing at another, but also: under what conditions is it guaranteed that a person existing at one time is identical with one existing at another? Noonan and Curtis (in Noonan 2012 and Curtis and Noonan 2015) suggest reformulating this question as: Which relations satisfy the following schema 'Necessarily, if $x$ is a person then if $R x t t *_{x}$ exists at $t$ and $t *$ '? I suggest that it is better captured by the following:

P2: Which relations R satisfy 'Necessarily, if $x$ is a person then [if $x$ exists at $t$ then $\left\{\right.$ if $y$ is a person and exists at $t *$ and $\left.\mathrm{Rx} t y t^{*} x=y\right\}$ ]'?

This question, like P1, is one about the conditions of personhood. Appealing to it we can give an account of reductionism.

P2 can be contrasted with P2-minus (so-called because it omits the first antecedent of the $\mathrm{P} 2$ schema): 
P2-minus: Which relations $\mathrm{R}$ satisfy 'Necessarily, if $x$ exists at $t$ then \{if $y$ is a person and exists at $t *$ and $\left.\mathrm{R} x t y t^{*} x=y\right\}$ '?

If a relation $\mathrm{R}$ satisfies the $\mathrm{P} 2$ schema and also the $\mathrm{P} 2$-minus schema the sentence resulting from the schema in question P2 tells us nothing about persons in particular that distinguishes them from other sorts of thing. Let us say that when a relation satisfies the schema in $\mathrm{P} 2$ but not the schema in $\mathrm{P} 2$-minus, so that it is not possible that a person is a counter-example to the sentence resulting from the P2-minus schema, but it is possible that some things of some other sorts are, the relation gives a sortally specific preservation condition for persons.

Now we can offer an account of reductionism. Reductionism is the view that (a) there are non-trivial, non-redundant, non-identityinvolving diachronic constraints on personhood and also (b) there is a sortally specific preservation condition for persons. Non-reductionism is view that there are not.

Most complex theorists are reductionists. As noted, Shoemaker is an example. He not only holds that a series of property-instances that is the career of a persisting person must have causal relations and relations of counterfactual dependence between successive members, he also holds that 'there is something which constitutes' the persistence of persons, that is, that there is a sufficient condition for a series of events being the career of a persisting person as well as a necessary condition (2012:129).

Perhaps Baker (2012) is an exception. Her 'not so-simple' simple view may be, in my terms, a non-reductionist instance of the complex view, or, as we might put it, a not-so-complex complex view. She writes 'On the one hand, I am not a reductionist about persons: I do not believe that personhood can be understood in sub-personal or non-personal terms, and hence I do not believe that there are noncircular informative necessary and sufficient conditions for a person identified at one time to be the same person as a person identified at a different time' (2012: 180). She goes on 'a person is a being with a first-person perspective essentially ... a person persists when and only when her first-person perspective is exemplified' (2012: 182). She adds, 'this condition for personal identity over time is not informative inasmuch as reference to the person is made in the explicans. Hence, this is a simple view. However, there is a necessary condition 
for exemplifying a robust first-person perspective'. She thus appears not to think that there is an informative sufficient condition of personal persistence. In fact she states in a footnote that she thinks her position is close to what Noonan calls (in his 2003: 97) the 'unoccupied position', which is actually the position of someone who is, in present terms, a non-reductionist complex theorist. ${ }^{5}$

I want to end with a brief discussion of the relation between reductionism and perdurantism and distinguish two versions of perdurantist reductionism, the Lewisean and the Parfitian.

Some reductionists reject perdurantism, the position that persons and other persisting things have temporal parts. Shoemaker (2012: 133) clearly does. 'There is no need,' he writes, 'to equate personstages ... with "time slices" of persons - one can think of a personstage as just the total state of a person at a time. A state of a thing is not a part of it, and the fact that a series of person-stages has temporal parts does not imply that persons have temporal parts'.

Some reductionists are perdurantists. This was, of course, true of Lewis, the great defender of perdurantism, and also Parfit. Perdurantist reductionism is a step towards a Humean 'bundle theory', according to which persons are bundles of causally related 'perceptions', that is, mental occurrences. But there is still a gap, as Lewis (1983: 77) in effect emphasizes: 'When I say that persons are maximal R-interrelated aggregates of person-stages I do not claim to be reducing "constructs" to "more basic" entities... Similarly, I think it is an informative necessary truth that trains are maximal aggregates of cars interrelated by the ancestral of the relation of being coupled together... But I do not think of this as a reduction to the basic'. Elsewhere he explains what he means by a person-stage: 'a personstage is a physical object, just as a person is.... It does many of the same things that a person does: it talks and walks and thinks, it has beliefs and desires, it has a size and shape and location. It even has a temporal duration. But only a brief one.... Hence a stage cannot do everything that a person can do, for it cannot do those things a person does over a longish interval' (1983: 76). As Lewis here

\footnotetext{
${ }^{5}$ Noonan describes the unoccupied position thus: 'there are informatively specifiable necessary conditions of personal identity over time, but no informatively specifiable sufficient conditions' (his italics).
} 
illustrates, a perdurantist may still wish to say that person-stages are subjects of experience, as persons are, and to be distinguished from their experiences, which are, in the language of Shoemaker (1985), experiencings and adjectival on experiencers, as grins are grinnings and adjectival on grinners. Parfit, following Hume, appears to reject this dependence claim; at one point he proposes to use the word 'event' rather than 'state' to refer to experiences precisely because a state must be a state of some entity and this is not true of events (1984:211).

So there are four views to be distinguished, each entailed by but not entailing the next: the complex view, reductionism, perdurantist reductionism and finally Parfitian/Humean Reductionism, which adds to the previous view the thesis that mental states are ontologically prior to persons, as, on Hume's view, perceptions are. But my main aim in this section has been to establish that there is logical space between denying the simple view Swinburne and Chisholm defend, and committing to reductionism.

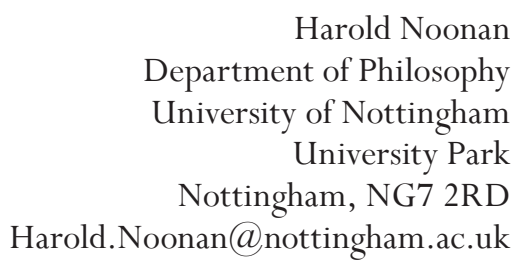

\section{References}

Baker, Lynne Rudder. 2012. Personal identity: a not-so-simple simple view. In Personal Identity: Complex or Simple?, edited by G. Gasser and M. Stefan, pp. 179-91. Cambridge: Cambridge University Press.

Butler, Joseph. 1736. Of personal identity. In Personal Identity, edited by J. Perry, pp. 99-105. Berkeley: University of California Press.

Chisholm, Roderick. 1969. The loose and popular and the strict and philosophical senses of identity. In Perception and Personal Identity, edited by N. S. Care and R. H. Grimm. Cleveland: The Press of Case Western Reserve University.

Curtis, Ben; and Noonan, Harold. 2015. Identity over time, constitution and the problem of personal identity. In The Constitution of Phenomenal Consciousness. Advances in consciousness research 92, edited by S.M. Miller, pp. 348-71. Amsterdam, The Netherlands: John Benjamins Publishing 
Company.

Hume David. 1739. A Treatise of Human Nature, edited by L.A. Selby-Bigge. Oxford: Clarendon Press

Lewis, David Kellogg. 1976. Survival and identity. In The Identities of Persons, edited by A.O. Rorty. Berkeley: University of California Press.

Lewis, David Kellogg. 1983. Philosophical Papers, vol. 1. Oxford: Oxford University Press.

Lewis, David Kellogg. 1986. On the Plurality of Worlds. Oxford: Blackwell.

Locke, John. 1694. An Essay Concerning Human Understanding, edited by Yolton. London: Dent, 1961.

Madell, Geoffrey. 1981. The Identity of the Self. Edinburgh: Edinburgh University Press.

Noonan, Harold. 2003. Personal Identity. London: Routledge.

Noonan, Harold. 2011. The complex and simple views of personal identity. Analysis 71: 72-7.

Noonan, Harold. 2012. Personal identity and its perplexities. In Personal Identity: Complex or Simple?, edited by G. Gasser and M. Stefan, pp. 82-101. Cambridge: Cambridge University Press.

Olson, Eric. 1997. The Human Animal: Identity without Psychology. Oxford: Oxford University Press.

Olson, Eric. 2012. In search of the simple view. In Personal Identity: Complex or Simple?, edited by G. Gasser and M. Stefan, pp. 44-62. Cambridge: Cambridge University Press.

Parfit, Derek. 1982. Personal identity and rationality. Synthese 53: 227-41.

Parfit, Derek. 1984. Reasons and Persons. Oxford: Clarendon Press.

Reid, Thomas. 1785. Essays on the Intellectual Powers of Man, edited by A. D. Woozley, London: Macmillan, 1941.

Shoemaker, Sydney. 1984. Identity, Cause and Mind, Oxford: Clarendon Press.

Shoemaker, Sydney. 1985. Critical notice of Reasons and Persons. Mind 94: 443-53.

Shoemaker, Sydney. 2012. Against simplicity. In Personal Identity: Complex or Simple?, edited by G. Gasser and M. Stefan, pp. 123-36. Cambridge: Cambridge University Press.

Shoemaker, Sydney; and Swinburne, Richard. 1984. Personal Identity. Oxford: Blackwell.

Swinburne, Richard. 1984. Personal identity: the dualist theory. In Personal identity, edited by S. Shoemaker and R. Swinburne, pp. 1-66). Oxford: Blackwell.

Swinburne, Richard. 2012. How to determine which is the true theory of personal identity. In Personal Identity: Complex or Simple?, edited by G. Gasser and M. Stefan, pp. 105-22). Cambridge: Cambridge University Press. 